\title{
A INCLUSÃO ESCOLAR DOS ALUNOS COM AUTISMO
}

\author{
Ana Cássia de Oliveira Gobbo ${ }^{1}$ \\ Fabio José Antonio da Silva ${ }^{2}$
}

\begin{abstract}
RESUMO: A pesquisa deste Artigo tem como objeto conceituar o termo autismo, bem como suas respectivas características físicas e comportamentais, considerando suas causas e possíveis tratamentos, para que possa se compreender elementos necessários para a compreensão da conduta do aluno portador da síndrome do autismo, de forma que os educadores juntamente com a equipe técnica possam criar novas metodologias didático/pedagógicas que enriqueçam o processo de ensino/aprendizagem do aluno autista, respeitando assim suas individualidades e correspondendo assim às expectativas da educação inclusiva, de forma a contemplar uma nova época para a educação no País, de modo a propiciar de forma efetiva a idealização de uma escola democrática, diversificada e aberta a todos.
\end{abstract}

Palavras-Chave: Autismo, Inclusão Escolar, Escola Especial.

ABSTRACT: The monographic study aims to conceptualize the term autism, as well as their respective physical and behavioral characteristics, considering its causes and possible treatments, so you can understand elements necessary for understanding the behavior of a student of the syndrome of autism, so that educators together with the technical staff can create new instructional / teaching methodologies that enhance the teaching / learning process of the autistic student, thereby respecting their individuality and corresponding thus ASA expectations of inclusive education in order to contemplate a new era for education in the country in order to provide an effective way, the idealization of a democratic school, diverse and open to all.

Keywords: Autism, Inclusion School, Special School.

\section{INTRODUÇÃO}

Considera-se que o autismo seja uma desordem que ocorre na criança enquanto jovem, o que a leva a comprometer o desenvolvimento das relações sociais normais, compulsivamente e ritualística, o que impede que desenvolva sua inteligência normal. A

1 Graduação em Pedagogia - UNOPAR. Graduação em Educação Fisica - UNOPAR. Servidora Pública Municipal - Prefeitura Municipal de São Sebastião da Amoreira/PR

2 Profissional de Educação Física. Mestre em Educação. Doutorando em Educação Física. CV: http://lattes.cnpq.br/3576574791707183 
maioria dos casos não apresenta nenhuma causa óbvia, acredita-se que alguns possam estar associados a umas infecções virais como a fenilcetonúria e a síndrome do X frágil.

A inclusão da criança com autismo no ambiente escolar é complexa, uma vez que a criança autista prefere a solidão, pois é resistente a relações sociais, principalmente àquelas mais próximas como o abraço, o contato olho no olho, a mudanças, assim a sua inclusão escolar deve ser analisada e planejada, para queela não se torne um aluno excluído em sala de aula.

Assim o Artigo pretende expor a área que atende o aluno que apresenta o quadro do autismo, seus comprometimentos, tipos de atendimentos, contexto da escola, aspecto que pode prejudicar o aluno, comportamento, recursose a Escola Especial. A pesquisa irá considerar também o autismo na sociedade, na escola, na família, bem como programas de desenvolvimento para o autista.

\begin{abstract}
Ao nos propormos a comentar o atendimento dispensado aos excepcionais, particularmente aqueles que apresentam deficiências, julgamos que seria de maior utilidade que traçar um perfil histórico, mostrando a ordem cronológica da concretização das ações sociais em diferentes sociedades, evidencia as atitudes sociais não apenas como fases evolutivas, mas também como dimensões que podem ocorrer, concomitantemente em um mesmo momento, em uma mesma sociedade. A razão disto é que embora se possa constatar que as atitudes sociais em relação às pessoas portadoras de deficiências vêm evoluindo em decorrência de diversos fatores, particularmente o avanço das ciências eda tecnologia, ao mesmo tempo se verifica a ocorrência de atitudes distintas num mesmo momento histórico e num mesmo lugar. (MAZZOTA, 1977, p.2)
\end{abstract}

Ao nos propormos a comentar o atendimento dispensado aos excepcionais, particularmente àqueles que apresentam deficiências, julga-se ser de utilidade traçar um perfil histórico, mostrando a ordem cronológica da concretização das ações sociais em diferentes sociedades, evidenciar as atitudes sociais nãoapenas como fases evolutivas, mas também como dimensões que podem ocorrer, concomitantemente em um mesmo momento,

Embora acreditando que as pessoas portadoras de deficiências são incapacitadas, e que, por isso mesmo, elas não podem ter uma participação ativa na vida da comunidade, algumas ações são empreendidas em favor dessas pessoas, organizando-se serviços de assistência quer refletem atitudes sociais marcadas por um sentido filantrópico, paternalista e humanitário. Para prestar tal assistência, basta pessoa bondosas ou de bom coração que, em nome do princípio cristão de solidariedade humana, procuram proporcionar conforto e bem-estar aos portadores de deficiências, ou em outras palavras, dar proteção aos deficientes. (MAZZOTA, 1977, p. 3) 
A Educação Especial possibilita uma formação voltada à cidadania do indivíduo e por ser tão importante é parte integrante e indistinta do sistemaeducacional que se realiza em todos os níveis de ensino. Dessa forma, a educação especial propõe a realização de práticas pedagógicas que visem a diversidade dos alunos, por meio da análise da educação especial na educação escolar, percebe-se que sua ação trabalha todos para a educação infantil, o ensino médio e educação fundamental, bem como as demais modalidades.

Nos últimos anos, a educação especial está sofrendo muitas mudanças, principalmente com relação à intervenção pedagógica como na área específica do conhecimento, pois percebe-se novas reformulações, retificações, derivações e práticas. Com essas mudanças surge o termo necessidades educacionais especiais que como a expressão diz é preciso que hajam ajudaspedagógicas ou serviços especiais.

A inclusão é igualmente um motivo que implica o aprimoramento da formação dos professores para realizar propostas de ensino inclusivo etambém um pretexto para que a escola se modernize, atendendo às exigências de uma sociedade, que não admite preconceitos, discriminação, barreiras entre seres, povos, culturas (MANTOAN, 1997, p. 94)

Percebe- se que a escola é um espaço onde o indivíduo aprende a desenvolver a

cidadania de forma consciente de seus direitos e deveres no exercício da convivência coletiva. É no ambiente escolar que a criança começa seus primeiros contatos com a sociedade, pois passa a conviver com um contexto diversificado, quefoge dos padrões familiares. Assim a criança aprende a analisar e criticar arealidade, conhecendo regras e dinâmicas sociais.

Segundo Mrech (1998) a prática pedagógica educativa inclusivanecessita de auxilio de instrumentos técnicos, toda a equipe escolar deve receber orientações didático/pedagógicas para que desenvolvam novos papéis, e condições para criação de novas formas para compor o processo de ensino/aprendizagem que satisfaçam às necessidades educativas dos alunos.

\section{O AUTISTA E A INCLUSÃO}

Para o desenvolvimento do autista é necessário que os pais explorem a capacidade dos filhos portadores do autismo, de modo que a convivência seja uma forma de vencer as barreiras, pois o ambiente escolar é sem dúvida uma barreira a ser vencida, pois há sempre a questão do olhar e do pensamento alheio.

A reação dos pais de crianças em relação à criança autista é mínima, pois ela quase 
não corresponde a estímulos e não se relaciona normalmente com os outros. Os pais do autista devem ser auxiliados por um trabalho de acompanhamento e preparação da comunidade escolar para receber esta criança.

O avanço em uma educação inclusiva poderá estar comprometido se os pais não derem atenção devida à criança, pois quanto mais cedo diagnosticada a doença, maiores serão as chances de progresso na educação inclusiva. A presença da criança autista na classe comum de ensino regular é muito importante para o seu próprio desenvolvimento.

Por isso, o movimento inclusivo nas escolas, por mais que seja ainda muito contestado e de caráter ameaçador de toda e qualquer mudança, especialmente no meio educacional, é irresistível e convence a todos pela lógica de seu desenvolvimento social. Sendo assim, o futuro de escolas inclusivas está dependendo de uma expansão rápida, para que a idéia de compromisso de transformação desta escola seja concretizada, para se adequar aos novos tempos.

A nova lei de diretrizes e bases $n^{\circ} 9394 / 96$, propõem em seus artigos 58, 59, 6o que as crianças excepcionais tenham acesso às classes comuns das escolas ditas normais públicas ou particulares. As escolas ou instituições especiais devem ser coadjuvantes no processo educacional destas crianças e recusar um luno portador de necessidades educativas especiais é crime.

Posteriormente é necessário o debate sobre qual será o melhor processo. Existe também a necessidade de preparação de professores e de outras crianças para evitar a discriminação. A esta problemática do ensino inclusivo, o profissional pedagógico torna-se incapaz, frustrado e freqüentemente encobre sensações, alegando que seu trabalho é o melhor e se fecha muita das vezes para experimentar outras formas de aprendizado. Se o trabalho multidisciplinar é difícil nesta área por causa dos poucos resultados satisfatórios, ele se torna ainda complexo e os atritos aos diferentes tipos de profissionais desta área mais frequentes. Ainda existe muita resistência dos professores à mudança, pois acreditam que a educação igualitária seria apenas uma utopia. Uma equipe técnica especializada é essencial para que o interesse seja mantido. Esta educação maisque uma tendência, é uma necessidade real para um melhor atendimento de todas as crianças, não apenas aos portadores de necessidades educativas especiais. 
Inúmeras propostas são sugeridas aos problemas relacionados à educação inclusiva dos portadores de autismo, pois estes necessitam de uma dupla assistência educativa, devido às dificuldades em se adaptarem a ambientes rotineiros. Ainda que se proponha a inclusão, corre-se o risco da segregação. Entretanto esses riscos não devem levar à estagnação e nem devem ser tomados como limites, mas sim como desafios para novas propostas. E que estas possam serplanejadas cuidadosamente, pois visa à preparação de toda equipe técnica para que no futuro próximo se possa perceber que houve realmente a inclusão.

A problemática de se conseguir adequar os alunos autistas à diversidade dos conteúdos também está relacionada ao fato da escola regular assumir junto à sociedade sua imagem de escola inclusiva, comprometida com o ensino e aprendizagem, buscando trabalhar dentro de uma integração.

A escola aberta para todos não é apenas uma meta a ser alcançada, mas também um problema na educação inclusiva, pois a escola inclusiva deve ser composta por um quadro funcional qualificado e comprometido com esta educação para proporcionar ao aluno autista sempre que necessário um acompanhamento paralelo.

Este acompanhamento deve propiciar suporte aos conteúdos nãoassimilados pelos alunos, haja vista suas dificuldades de relacionamento que interferem na aprendizagem, visando sempre o nível de possibilidade de desenvolvimento explorando possibilidades por meio de atividades, sejam elas abertas ou medindo seus interesses.

O conceito atual de inclusão se refere à vida social e educativa e todos os alunos devem ser incluídos nas escolas regulares e não somente colocados na "corrente principal".

O objetivo primordial da educação inclusiva é desenvolver a atenção, escolhendo tarefas que as desenvolvam e, em seguida, cultivar a concentração, a persistência, a paciência como atributos da atenção, fazendo assim com que esta criança interaja com o mundo lá fora, dentro de uma escola normal.

A inclusão causa uma mudança de perspectiva educacional, pois nãose limita a ajudar somente alunos que apresentam dificuldades na escola, mas atodo corpo técnico presente dentro da instituição, para que obtenham sucesso na corrente educativa geral.

As escolas inclusivas propõem um modo de se constituir o sistema educacional que considera as necessidades de todos os alunos e que é estruturado em função dessas 
necessidades.

\subsection{Comportamento e Sociabilidade}

Segundo o Manual Diagnóstico e Estatístico de TranstornosMentais (DSM-IV) as características principais do Autismo é a presença de umdesenvolvimento anormal na interação social e da comunicação e um repertório muito restrito de atividades e interesses.

O comprometimento da interação social recíproca é abrangente, ao mesmo tempo persistente, o que pode haver levar ao desenvolvimento de relacionamentos fracassados com seus pares que sejam próprios do nível de desenvolvimento do indivíduo em diferentes idades; uma ausência da busca espontânea pelo prazer compartilhado, interesses ou realizações com outras pessoas. Os indivíduos que apresentam este transtorno ignoram outras crianças,pois podem negligenciar as necessidades alheias.

As dificuldades da comunicação atingem as habilidades verbais e não verbal o que ocorre atraso ou ausência total do desenvolvimento da fala. Nos indivíduos que conseguem falar, a capacidade de iniciar ou manter uma conversação é bastante comprometido devido o uso estereotipado e repetitivo da linguagem. Os indivíduos que apresentam este transtorno possuem uma adesão aparentemente inflexível à rotinas ou rituais específicos e não funcional preocupação persistente com partes de objetos ou maneirismos motores repetitivo.

A Associação dos Amigos da criança Autista (AMAP) afirma que a melhor para compreender o autismo é definir algumas características catalogadas por uma instituição que trabalha diretamente com este tema, dessa forma há a possibilidade de se ampliar esses conhecimentos. Existem algumas características comportamentais da criança autista adaptadas pela AMA-SP. São elas: resistência a métodos normais de ensino, risos e gargalhadas inadequadas; ausência de medo deperigos reais; aparente insensibilidade à dor; forma de brincar estranha eintermitente; não mantém contato visual; conduta distante e retraída; indica suas necessidades através de gestos; age como se fosse surdo; crises de choro e extrema angústia por razões não discerníveis; dificuldades em se misturar comoutras crianças; resiste a mudanças de rotina; habilidades motoras finas / grossas desniveladas; hiperatividade física marcante e extrema passividade; repetição de frases ou palavras; apego inadequado a objetos. 


\subsubsection{Condutas Típicas Mais Comumente Descritas}

Segundo o Projeto Escola Viva (2002), as condutas típicas mais comuns em sala de aula são: os disturbios de atenção, a hiperatividade, a impulsividade, o alheamento ea agressividade física ou verbal.

\section{- Os distúrbios de atenção}

Neste caso os alunos apresentam dificuldades em atender aos estímulos relevantes de uma situação, assim olham para outro estímulo presente. Essas crianças movimentam a cabeça o tempo todo, apresentam dificuldades na execução das atividades. Outros respondem aos aspectos limitados da realidade.

\section{- Hiperatividade}

Neste caso a criança hiperativa, mostra uma incapacidade de controlar seu comportamento motor de acordo com as exigências nas diversas situações. Não possui habilidade nas agitação motora, o que acaba por limitar suas ações e tarefas.

\section{- Impulsividade}

Neste caso a criança é impulsiva devido às respostas impulsivas, não para pensar, toma uma decisão de forma brusca por meio de ação motora ou verbal.

\section{- Alheamento}

Neste caso as crianças se mantém isoladas, sem contato com outras crianças, essa mesma dificuldade é presente também na interação com o ambiente sociocultural. Mesmo em sua manifestação mais leve a criança não apresenta contato verbal, não brinca com outras crianças e mostra falta de interesse por estímulos provocados pelo ambiente e por outras pessoas. 


\section{- Agressividade Física ou Verbal}

Neste caso a criança apresenta uma agressividade física e/ou verbal, que propicia ações destrutivas a si mesmo, aos outros e ao ambiente.

Nestes comportamentos estão presentes o gritar, o xingar, usar a linguagem de forma abusiva, ameaçar os outros, fazer declarações destrutivas de si mesmo, bater nos outros, beliscar, puxar os cabelos, restringir fisicamente e esmurrar, esses são alguns dos comportamentos agressivos apresentados pela criança com agressividade.

Entretanto a agressividade passa a ser uma conduta típica, pela manifestação de sua intensidade, frequência, duração, podendo variar com manifestações negativistas caracterizadas com violência, brutalidade, destruição, danos físicos a si próprio e aos outros.

\subsection{Histórico de Autismo}

O pesquisador Kanner realizou no ano de 1943 um estudo, ondedescreveu a condição de II crianças consideradas especiais. O termo Esquizofrenia infantil neste período era considerado sinônimo de Psicose Infantil. Essas criançaseram observadas por Kanner, ele identificou algumas características especiais ediferentes das crianças esquizofrênicas, pois apresentava incapacidade de serelacionarem com outras pessoas e com os objetos, além de apresentaremdificuldades no desenvolvimento da linguagem, muitas não falavam, enquanto que as poucas que falavam apresentavam ecolalia, inversão pronominal e o concretismo.

O comportamento das crianças em estudo, era caracterizado por atos repetitivos e estereotipados, assim não simpatizavam com mudanças de ambiente, gostavam de um contexto inanimado. $O$ autismo se referia à características de isolamento e auto concentração das crianças sugerindo algumas associações com a esquizofrenia.

No termino da década de 70 Rutter explicou o Transtorno Autista afirmando ser uma síndrome com precocidade de início e por perturbações das relações afetivas com o meio, apresentava incapacidade de estabelecer qualquer relação afetiva e não correspondia aos estímulos do meio. Kanner assim compreendeu que nestes casos o termo autismo não deveria referir-se a um afastamento da realidade com predominância do mundo interior, como se diziaacontecer na esquizofrenia. Portanto, mesmo para ele não haveria no autismo infantil 
um fechamento do paciente sobre si mesmo, mas sim, um tipo particular e específico de contato do paciente com o mundo exterior.

$\mathrm{Na}$ década de 5o, os autores norte-americanos não queriam empregar o termo psicose, assim as crianças que apresentavam sintomas psicóticos eram consideradas crianças atípicas ou possuidoras de um desenvolvimento atípico ou excepcional.

Com a década de 6o, as psicoses infantis foram compreendidas de duas formas: da primeira infância e da segunda infância. Nas psicoses da primeira infância tem-se o Autismo Infantil Precoce, sendo entendido como um transtorno primário. E as psicoses de segunda infância são lesões cerebrais ou retardamento mental.

$\mathrm{Na}$ França, o conceito de Esquizofrenia Infantil foi substituído pelo conceito de Psicose Infantil. O Autismo Infantil é uma psicose, este termo psicose infantil precoce foi aplicado às psicoses que se iniciam na primeira infância. AEsquizofrenia Infantil ficou reservada aos quadros com início mais tardios que surgem depois da criança ter passado por um desenvolvimento normal.

\subsection{Diagnóstico}

Um diagnóstico médico preciso do transtorno autista exigiria que a criança fosse examinada, tanto no aspecto físico como psiconeurológico. Atualmenteprocedem-se alguns estudos bioquímicos, genéticos e cromossômicos, eletroencefalográficos, de imagens cerebrais anatômicas e funcionais e outros que possam esclarecer o quadro de diagnóstico do autismo, este continua sendo predominantemente clínico e não poderá ser feito puramente com base em testes ou algumas escalas de avaliação.

Os transtornos invasivos do desenvolvimento se caracterizam por prejuízo severo e invasivo nas habilidades da interação social, nas habilidades de comunicação, nos comportamentos, nos interesses e atividades. Acredita-se que os prejuízos qualitativos que proporcionam tais condições representam um desvio significativo em relação ao desenvolvimento ou idade mental do indivíduo.

Esses transtornos se apresentam logo nos primeiros anos de vida e na maioria das vezes estão associados com algum grau de retardo mental. Os transtornos invasivos do desenvolvimento são observados junto com um grupo de várias outras condições médicas 
gerais, como anormalidades cromossômicas, infecções congênitas e normalidades estruturais do sistema nervoso central.

Os transtornos invasivos do desenvolvimento são distintos da esquizofrenia. Entretanto, um indivíduo com transtorno invasivo do desenvolvimento pode mais tarde também desenvolver a esquizofrenia.

O autista apresenta comportamentos característicos como: hábitos anormais, resistências às mudanças, apego à objetos, brincadeiras estereotipadas.A capacidade de pensamento abstrato ou simbólico é muito baixa, sendo que o nível de inteligência irá variar sendo o nível de retardo.

O desempenho da criança autista é habitualmente melhor para as atividades que exigem aptidões mnêmicas ou viso espaciais automáticas, nas atividades que necessitam das aptidões simbólicas ou linguísticas, o autista terá sempre um grau de dificuldades significativo.

O Autismo Infantil trata-se de "um transtorno invasivo" de desenvolvimento definido pela existência do desenvolvimento anormal ou comprometido que se manifesta antes da idade de 3 anos de idade e pelo tipo de funcionamento anormal nas três áreas de interação social: comunicação e comportamento restrito e repetitivo. Acredita-se que o transtorno se apresente emgarotos três ou quatro vezes mais do que em meninas.

\subsection{Causas}

O transtorno autista necessita de maiores explicações médicas para seu aparecimento. diante dessa perspectiva, alguns pesquisadores acreditaram que a relação de frieza emocional dos pais poderia promover o desenvolvimento do autismo.

Kanner também acreditava que as atitudes e comportamentos dos pais poderiam influir no aparecimento da síndrome, pois já havia estudado II pacientes iniciais, estes tinham pais intelectualizados e emocionalmente frios, na grande maioria dos casos.

Entretanto, apesar de ser muito importante a dinâmica emocional familiar na vida de uma criança, sua falta é um elemento suficiente para justificar o seu aparecimento. $O$ autismo não parece ser em sua essência, um transtorno adquirido.

Os trabalhos realizados no mundo todo revelaram teorias psicológicas e 
psicodinâmicas para explicar o autismo e as psicoses infantis em uma época onde a investigação funcional e bioquímica do sistema nervoso central era ainda muito incompleta. Atualmente, o autismo tem sido definido como uma síndrome comportamental resultante de um quadro orgânico.

O espectro autismo é visto como processo contínuo, que vai do grau leve ao severo. Há uma associação entre autismo e retardo mental, desde o leve até o severo, considera-se que a gravidade do retardo mental não deva estar associadaà gravidade do autismo.

A palavra autismo atualmente pode ser associada a diversas síndromes. os sintomas variam amplamente, o que explica por que atualmente tem se referido ao autismo como um espectro de transtornos. Este espectro apresenta a tríade de comprometimentos que confere características comuns a todos eles. Alguns são diagnosticados simplesmente como autismo, traços autísticos, e outros, ou Síndrome de Asperger.

Apesar de ter sido descrita por Hans Asperger em 1944 no artigo científico "Psicopatologia Autistica na Infância” foi em I994 que a Síndrome deAsperger foi incluída no DSM-IV com critérios para diagnóstico. Algumas das características peculiares mais frequentemente apresentadas pelos portadores da Síndrome de Asperger são: atraso na fala, mas com desenvolvimento fluente da linguagem verbal antes do 5 anos e geralmente com dificuldades na linguagem, Linguagem pedante e rebuscada, Ecolalia ou repetição de palavras ou frases ouvidas de outros e voz pouco emotiva e sem entonação.

\subsection{O Autismo e a Sociedade}

Os autistas, principalmente aqueles com síndrome de Asperger, e suas famílias, sofrem grandes desafios ao longo da vida. A criação de um ambiente facilitador para o autismo é necessário para os autistas e também para suas famílias. È preciso aumentar conhecimento sobre o autismo na sociedade, tanto em termos gerais como específicos.

O autismo não é uma condição extremamente incomum, na verdade afeta no mínimo, mais de uma em cada 200 crianças. Isto significa que o autismo incluindo a síndrome de Asperger, uma síndrome que está muito presente na sociedade. Uma sociedade moderna necessita de administradores que forneçam estrutura necessária para uma vida 
digna para pessoas com autismo.

O autismo geralmente causa problemas graves sociais/de comunicação e comportamentais/de imaginação, que causam impacto em muitos aspectos da vida cotidiana, incluindo as relações com outras pessoas e com a família, o aprendizado e o ajuste escolar e psicossocial.

O Conhecimento especializado sobre autismo e síndrome de Asperger, é necessário para os educadores, pois assim evitarão complicações secundárias tais como ansiedade, confusão, colapso da comunicação e falha em atingir todo o potencial de aprendizado do autista. Da mesma forma os pediatras, neurologistas infantis e psiquiatras infantis também devem saber o básico sobre autismo, e alguns deles precisam se especializar no campo.

Os problemas psiquiátricos associados incluindo déficits de atenção, hiperatividade, juntamente com comportamentos auto agressivos, e estados de confusão que podem ser mal entendidos como psicose/esquizofrenia e muitos dos indivíduos que tem alto desempenho cognitivo são diagnosticados como se sofressem de distúrbios de personalidade, isto significa que os psiquiatras de adultosdevem ter treinamento e habilidades clínicas no campo do

autismo. Pessoas com autismo precisam de ajuda para pavimentar a estrada que leva à sociedade favorável ao autismo.

\section{CONSIDERAÇÕES FINAIS}

A pesquisa buscou subsídios necessários para a compreensão da inclusão de crianças autistas em escolas regulares de ensino. Entretanto, ao considerar a grande complexidade da síndrome do autismo, a monografia buscou primeiramente esclarecer conceitos sobre o seu significado, suas características de bases de como se diagnostica uma criança com Síndrome do Autismo.

Ao tratar sobre a inclusão de portadores da síndrome do autismo, os objetivos foram alcançados, pois o trabalho propôs informações e conhecimentos relacionados à compreensão da síndrome e sobre as possíveis barreiras quanto a inclusão dos alunos autistas na escola regular. A pesquisa procurou descrever as reações inusitadas e bizarras do autista bem como seu repertório comportamental.

Percebe-se que as escolas "inclusivas" que trabalham com crianças autistas, 
recebem-nas em salas separadas das outras crianças, é preciso que todos saibam que essas crianças vieram ao mundo com capacidade para travar contato afetivo normal com pessoas, da mesma forma como outras crianças também fazem.

É necessário desenvolver inúmeras reflexões, pois apesar do autismo apresentar muitas características comuns a outras síndromes, possui identidade muito diferenciada. Faz se necessário uma ação educativa comprometida com a cidadania e com a formação de uma sociedade mais democrática e menos excludente, para isso é necessário maior conscientização da sociedade em relação aos direitos dos indivíduos, principalmente aqueles com portadores da síndrome de autismo.

A escola inclusiva é uma tendência a ser efetivada neste início de terceiro milênio. Para que o processo de inclusão dos portadores desta síndrome possa de fato acontecer, exige-se um comprometimento da sociedade e do governo com a educação, só assim será possível minimizar os preconceitos e os entravesque permeiam os caminhos do desenvolvimento da cidadania para todos.

\section{REFERÊNCIAS BIBLIOGRÁFICAS}

\section{ALMEIDA, M. S. R. Buscando uma Escola Inclusiva.}

BALlONE, G. J. - Autismo Infantil, in. PsiqWeb, Psiquiatria Geral.

GAUDERER, Christian. Autismo e outros atrasos do desenvolvimento: Guiaprático para os pais e profissionais. Rio de Janeiro. 1997. Ed. REVINTER

GAUDERER, E. C. Autismo. Ed. Atheneu $3^{\text {a }}$ edição. 1993

KAPLAN, Harold I. Compêndio de Psiquiatria: Ciências do comportamento epsiquiatria clínica. 7.ed. Porto Alegre: Artes Médicas, 1997.

LAGE, Ana. Autismo Infantil: Revisão Bibliográfica. Fortaleza, 1984.

MANTOAN, M.T. E. Ser ou estar, eis a questão: explicando o déficit intelectual.Rio de Janeiro: WA, I997. 
MAZZOTA, M. J. S. Fundamentos de Educação Especial, Série Cadernos deEducação, Biblioteca Pioneira de Ciências Sociais, São Paulo, 1973.

MITTLER, P. Educação Inclusiva: Contextos sociais, aritmed, Porto Alegre, 2003.

MORAES, F. F. F. O Autismo na Perspectiva de uma Educação Inclusiva, Belém, Universidade da Amazônia, 2002.

MRECH, L. M. Psicanálise e Educação: novos operadores de leitura: São Paulo, Editora: Pioneira Educação, 1998.

PROJETO ESCOLA VIVA, Garantindo o Acesso e Permanência de Todos os Alunos na Escola, Reconhecendo os alunos que apresentam dificuldades acentuadas de aprendizagem, relacionadas a condutas típicas, Brasília, Ministério da Educação, Secretária de Educação Especial, 2002.

SALOMÃO, José; ASSUMPÇÃO, Francisco; e col. Autismo Infantil. São Paulo: Memmon, 1995 .

VOIVODIC, M. A. M A. Inclusão Escolar de Crianças com Síndrome de Down,Vozes, 2004 . 